\title{
LETTERS
}

\section{To act or not to act}

Being antiracist comes at a cost.

As Dr. Patrick outlined, ${ }^{1}$ CMAJ publishing antiracist scholarly commentary ${ }^{2}$ has been met with criticism. Similarly, medical learners can also face resistance when standing up for ourselves.

When a patient asked me if I eat bats, I ignored it. When I was assaulted and robbed by perpetrators targeting Asians, I shrugged off the correlation to race. When I got workplace comments on how I'm tall for a Chinese guy, I laughed with the rest of them. Should I have done more or advocated for myself? Should I have fought back? We are taught that racism is an important determinant of health, but I still fear negative consequences should I call it out. My desire to remain an impartial professional and team player are at odds with the voice in my head thinking, "That's not right." As Dr. Patrick mentioned, many are still hesitant to acknow- ledge the power of systemic racism, and it can be difficult to distinguish allies from enemies and everyone in between. Medical clerks are evaluated on subjective measures that can greatly affect our future careers. How can we advocate for racial justice when our own evaluator is the offender? When we are unsure if our selfadvocacy will elicit endorsement or eyerolls? Being labelled a problem student is a potential cost of being antiracist as a trainee - a risk that is tough to accept this early in my career.

Observing people in positions of power role modelling antiracism makes an immeasurable difference to learners fighting against the current of traditional medical culture. It takes any guesswork away and emboldens those downstream in the hierarchy. However, the question remains: how do we reach the point where being antiracist is not a professional gamble for learners? Will there always be such a cost?

\section{Geoffrey Lau BHSc}

Medical student, University of Toronto, Toronto, Ont.

\section{Renata Leong MDCM MHSc}

Family physician, St. Michael's Hospital, Toronto, Ont.

Cite as: CMAJ 2021 May 17;193:E738. doi: $10.1503 / \mathrm{cmaj} .78702$

\section{References}

1. Patrick K. CMAJ and antiracism. CMAJ 2021;193: E453-4.

2. Sharda S, Dhara A, Alam F. Not neutral: reimagining antiracism as a professional competence. CMAJ 2021;193:E101-2.

Competing interests: None declared.

Content licence: This is an Open Access article distributed in accordance with the terms of the Creative Commons Attribution (CC BY-NC-ND 4.0) licence, which permits use, distribution and reproduction in any medium, provided that the original publication is properly cited, the use is noncommercial (i.e., research or educational use), and no modifications or adaptations are made. See: https://creativecommons.org/ licenses/by-nc-nd/4.0/ 